January 1994

\title{
The Serotonin Theory of Depression
}

Christopher W. Kerr

Medical College of Ohio at Toledo

Follow this and additional works at: https://jdc.jefferson.edu/jeffjpsychiatry

Part of the Psychiatry Commons

Let us know how access to this document benefits you

\section{Recommended Citation}

Kerr, Christopher W. (1994) "The Serotonin Theory of Depression," Jefferson Journal of Psychiatry. Vol. 12 : Iss. 1 , Article 4.

DOI: https://doi.org/10.29046/JJP.012.1.001

Available at: https://jdc.jefferson.edu/jeffjpsychiatry/vol12/iss1/4

This Article is brought to you for free and open access by the Jefferson Digital Commons. The Jefferson Digital Commons is a service of Thomas Jefferson University's Center for Teaching and Learning (CTL). The Commons is a showcase for Jefferson books and journals, peer-reviewed scholarly publications, unique historical collections from the University archives, and teaching tools. The Jefferson Digital Commons allows researchers and interested readers anywhere in the world to learn about and keep up to date with Jefferson scholarship. This article has been accepted for inclusion in Jefferson Journal of Psychiatry by an authorized administrator of the Jefferson Digital Commons. For more information, please contact: JeffersonDigitalCommons@jefferson.edu. 


\title{
The Serotonin Theory of Depression
}

\author{
Christopher W. Kerr
}

\begin{abstract}
In its simplest form, the serotonin deficiency theory of depression postulates that there is a net reduction in serotonin transmission in depressive illness. The pathophysiological change may result from two different mechanisms. The first involves a decrease in serotonin (5-HT) availability which has the consequential effect of compensatory receptor up-regulation or supersensitivity. The second mechanism implies a primary defect in receptor activity and/ or signal transduction. The objective of this review is to analyze the serotonin system in depression as it relates to the above two postulates.
\end{abstract}

Chemical imbalances in the central nervous system (CNS) have long been thought to underlie fluctuations in mood. The amine hypothesis, that the pathophysiology of depression involves impairment of catecholamines, has been expanded to include the role of serotonin, or 5-hydroxytryptophan (5-HT). Through its widespread distribution within the neural axis, serotonin is thought to: "play a key role in the modulation of excessive stimuli of a wide variety and in the organization of appropriate responses. It has been suggested that the overall function of the serotoninergic system is to enable the organism to ward of feelings of fear, helplessness and depression (1)." Consistent with this hypothesis is the evidence that alterations in serotonin activity have a role in core behaviors which are also disturbed in affective illness $(1,2)$.

In its simplest form, the serotonin deficiency theory of depression postulates that there is a net reduction in serotonin transmission in depressive illness. The pathophysiological change may result from two different mechanisms. The first involves a decrease in 5-HT availability which has the consequential effect of compensatory receptor up-regulation or supersensitivity. The second mechanism implies a primary defect in receptor activity and/or signal transduction. Although the serotonin deficiency theory receives considerable support in explanations of depression, recent studies have suggested that some forms of human depression may be due to an excess of serotonin at the synapse (3). The objective of the following review is to analyze the serotonin system in depression as it relates to the above two postulates.

The search for the role of serotonin in depression has evolved from research on depression-related alterations in serotonin levels, to changes in 5-HT metabolism

Christopher W. Kerr is a fourth year medical student at the Medical College of Ohio at Toledo. This paper is the winning essay of the 1993 Kaplan Essay Contest for medical students and was presented at a symposium for medical students held in Cincinnati in October, 1993. 
and more recently to 5 -HT receptor studies. In the following review, the data will be described in a similar sequence. It is important to note that this discussion will include references to contradictions in experimental results. In part, this complexity reflects the challenge in isolating the action(s) of serotonin given its distribution in functionally discrete regions of the CNS (4). Furthermore, serotonin mediates a diverse array of physiological responses by interacting with several different 5-HT receptor subtypes as well as interacting with the actions of several nonserotoninergic systems $(5,6)$. The challenge in research, therefore, is to isolate the actions of 5-HT, as well as the effectiveness of drugs on this system, given the diversity in serotonin distribution as well as the heterogeneity of 5-HT receptors. With regard to the clinical findings, in part the contradiction in results reflects the difficulty in comparing individuals based on a subjective assessment of symptomatology despite the possibility of different diagnostic subgroups, associated etiologies and/or treatment exposure(s). This review will attempt to describe the role of serotonin while acknowledging the methodological difficulties and contradictions in findings.

\section{CSF AND BRAIN LEVELS OF 5-HT AND 5-HIAA}

The earliest studies which focused on the role of serotonin in depression measured the cerebrospinal fluid (CSF) concentration of serotonin or its major metabolite, 5-hydroxyindoleacetic acid (5-HIAA), as an index of serotoninergic activity. In humans, the level of CSF 5-HIAA has been found to correlate accurately with the concentration of 5-HIAA in the brain (7). Although some studies have found decreased levels of the serotonin metabolite in depressed patients others have failed to report significant differences when compared to normal controls $(8,9,10)$. Interestingly, antidepressant treatment with drugs which inhibit 5-HT uptake (e.g. imipramine, amitriptyline) decrease the CSF 5-HIAA level although the magnitude of the reduction does not correlate with the clinical responsiveness to medication (11). This action is predicted based on feedback effects involving increased post-synaptic activity and uptake with a subsequent decrease in serotonin.

In contrast to the above studies which focused on the depressed patient, CSF studies of suicide attempters report significant reductions in 5-HIAA (12). Moreover, suicide victims with definitive affective disorders represent a subgroup with significantly lowered CSF levels of 5-HIAA. Among this subgrouping the greatest reduction in C.SF 5-HIAA is associated with unipolar depression and absent in bipolar disorder. Additional studies report a distinction between violent versus nonviolent suicide with the lowest levels associated with violent suicide. This observation is difficult to interpret; nonetheless it has been suggested by one reviewer that "since the selection of suicide method is heavily dependent on availability and modeling, it is probable that the association is actually with the seriousness of intent or medical lethality of the method (13)." In addition to the studies focusing on metabolite levels, five of seven studies have reported a decrease in 5-HT or 5-HIAA levels within the brain of suicide victims or suicide attempters (12). The reduced levels were found localized to the brainstem with only one study reporting reductions in higher cortical centers. 
The reason for the discrepancies between regions are unknown. One possible explanation is that brainstem levels may reflect changes at the level of serotonin cell bodies, whereas cortical measures indicate some aspect of terminal activity in which basal levels are lower by comparison.

It is difficult to address the data discrepancies between those studies based on the purely depressed versus the suicide victim. There are several possible, but unproven explanations. First, reductions in brain serotonin may vary in magnitude between the depressive and suicidal states such that low CSF levels are not detected in the former, perhaps due to the limited sensitivity of the assay. Second, indices of serotonin may be transitory in nature and fluctuate according to diet, time of day, etc. Third, the trauma of suicide may be associated with metabolic alterations that are unrelated to the etiology of the depressive illness. In fact, given the distinctions between violent versus nonviolent methods of suicide, the suicide event itself may be an important and undefined variable in the findings. An additional concern lies in interpreting the anatomical finding of lowered serotonin content in the brains of suicide victims. There is some criticism that the serotonin being assayed may be in longer-term storage; therefore the functional importance may be unclear (13). Further, an alteration of the level of serotonin does not necessarily imply a change in the concentration of available or functionally effective serotonin. For example, a lowering of neuronal serotonin may be compensated by an increase in the number of post-synaptic receptors or an alteration in the release mechanism of 5-HT from the neuronal pool. In reviewing the literature, studies do not appear to have addressed the critical question concerning alterations in serotonin release (i.e. functional 5-HT) as a consequence of depression. Despite these criticisms, the data do suggest that there is an overall change towards a lower serotoninergic signal in those individuals attempting suicide.

\section{PLASMA TRYPTOPHAN}

Since the availability of tryptophan is the rate-limiting factor in the synthesis of neuronal serotonin, there have been numerous investigations concerning the concentrations of plasma tryptophan in unmedicated depressed patients. This work is based on the premise that a reduction in available tryptophan, possibly because of excessive peripheral metabolism, may underlie the reduction in 5-HT measured in the brains of some depressed patients $(1,13)$. The data concerning the levels of plasma tryptophan are conflicting, although some studies do report a decrease in plasma tryptophan (14).

A more definitive finding is the observation that normal control subjects demonstrate a positive correlation between basal levels of plasma tryptophan and the 5-HT metabolite 5-HIAA whereas depressed patients do not (1). In other words, in the depressed patient an increase in the substrate for serotonin (tryptophan) is not correlated with an increase in serotonin end-product (5-HIAA) in plasma. The lack of correlation may suggest that some depressed patients abnormally metabolize tryptophan in peripheral organ systems, thereby altering the CNS content of serotonin. 
However, firm conclusions are complicated by the fact that tryptophan may be sequestered (i.e. in liver and muscle tissue) and the exact origin of plasma 5-HIAA is unknown. Several studies have shown that large doses of tryptophan result in lower plasma levels of tryptophan in some depressed versus control subjects $(15,16)$. This suggests that in some cases of depression there is a more rapid clearance of tryptophan as opposed to an alteration in tryptophan breakdown. Indeed, subsequent experiments have demonstrated that some depressed patients have increased red cell transport of tryptophan and, when compared to normal controls, show a greater drop in arterial versus venous levels of tryptophan $(17,18)$. Thus, one interesting possibility suggests that increased peripheral uptake and clearance of tryptophan contributes to the neuronal deficiency of serotonin in depression.

The above findings support the serotonin deficiency hypothesis of depression and are corroborated by observations that alterations in the availability of tryptophan, or 5 -HT itself, influence the mood of depressed individuals $(20,21,22)$. In fact, one reviewer suggests that "the most pervasive evidence for the role of 5-HT in mood disorders is the effect of lowering brain 5-HT concentration in depressed patients and normals (1)." Inhibition of serotonin synthesis, through the administration of p-chlorophenylalanine, has been shown to rapidly induce a recurrence of the depressive episode in patients recovering from depression (19). Further, 15 of 21 antidepressant-treated depressed patients who received a tryptophan-free diet showed a substantial increase in depressive symptoms (20). However, this same paradigm improved the symptoms of 14 of 22 untreated depressed individuals. This latter finding is a direct challenge to the theory that too little serotonin underlies the continuation of depressive symptoms.

One critical factor that limits the usefulness of tryptophan-depletion studies concerns the fact that uptake of tryptophan is not limited to serotoninergic neurons and therefore plasma tryptophan may reflect variations in peripheral metabolism only. As well, depletion of tryptophan in normal individuals has been shown to have a mood-elevating effect (21). The differential effect of serotonin depletion in normal versus depressed individuals suggests that additional factors alter the manifestations of serotonin depletion within the CNS. In other words, the depletion of 5-HT in normal and depressed individuals results in opposite mood outcomes that imply differences in brain processing, perhaps because of variability of receptor-mediated events or serotoninergic neuronal release mechanisms.

Based on the premise that a reduction in tryptophan has a mood-lowering effect in some depressed patients, administration of tryptophan has been attempted as therapeutic treatment in depression. Unfortunately, tryptophan has rarely been found to elevate mood in depressive illness $(11,19)$. This appears to challenge the role of serotonin in depression exclusively in terms of a precursor deficiency. Given the therapeutic ineffectiveness of tryptophan alone, it is also difficult to resolve the beneficial action of some antidepressants which are commonly thought to raise available serotonin. Perhaps exogenous tryptophan requires metabolic processing and neuronal release mechanisms that are impaired in the depressed and which may be bypassed by the action of antidepressants. Specifically, many antidepressants block 
either the re-uptake or degradation of endogenous serotonin independent of neuronal processing.

While tryptophan alone has little therapeutic effect, tryptophan administration does enhance the effectiveness of some antidepressants $(2,22)$. For example, the effectiveness of MAO inhibitors is potentiated by tryptophan administration in some patients. One interpretation is that requirements for the tryptophan are increased in the drug-treated state and are unrelated to the etiology of the illness. That both MAO inhibitors and tryptophan act to increase available serotonin supports the theory that serotonin deficiency is a causal factor in some forms of depression.

There are also numerous reports that lithium carbonate improves the action of antidepressants in a number of patients (50\%) who fail to respond to antidepressant treatment alone $(2,22)$. Several authors suggest that lithium may also act to increase the effectiveness of serotonin transmission. Briefly, levels of neuroendocrine hormones are used to evaluate the activity of the serotonin system as $5-\mathrm{HT}$ is known to potentiate the release of hormones through its dense innervation to the hypothalamus. Using this model, lithium has been shown to increase patient and rodent responsiveness to serotonin and/or tryptophan as reflected by an increase in endocrine hormones such as prolactin and cortisol $(24,25,26)$. Although the use of neuroendocrine parameters does provide a window to brain function, the presence of a direct casual relationship is unclear. For example, the hypothalamic-pituitary axis is modulated by numerous neuroactive chemicals and physiological states. Therefore, lithium may act independent of serotonin to activate the hypothalamic axis or potentiate excitatory mediators (i.e. releasing factors) of this system.

In sum, the analysis of basal plasma tryptophan levels is inconclusive to date. However, when compared to normal controls, increases in tryptophan do not correlate with increases in plasma 5-HT metabolite levels in some depressed patients. The discrepancy between serotonin substrate (tryptophan) and metabolite (5-HIAA) may arise from alterations in metabolism or increased clearance, perhaps by nonneuronal organ systems. A reduction of tryptophan levels lowers the mood in some depressed patients and elevates mood in normal controls. Conversely, elevations in tryptophan levels have little, if any, mood altering action in the treatment of depression. This latter observation challenges the explanations of depression solely in terms of serotonin deficiency. However, in part, many antidepressants do appear to enhance the actions of serotonin although the specificity of this effect is unclear. Collectively, these studies point to an overall decrease in serotonin as a causal, yet not exclusive, factor in some forms of depressive illness.

\section{SEROTONIN UPTAKE SITES AND REEEPTORS}

Another approach for assessing the serotonin system has involved the measurement of serotonin receptor content in post-mortem brain tissue and blood platelets. The following discussion is subdivided into two sections to clarify the distinction between the data pertaining to the uptake of serotonin versus that related to $5-\mathrm{HT}$ 
receptors which mediate the actions of serotonin. The first section will review experiments which involve the assay of ligand binding to 5-HT uptake sites on blood platelets and serotoninergic neurons. It is important to clarify that neuronal serotonin uptake sites are distributed on serotoninergic presynaptic terminals. Therefore, a reduction in 5-HT uptake sites refers only to a loss of serotonin storage (presynaptically) as opposed to a direct loss in postsynaptic effect. The second section describes alterations in serotonin receptors which are distributed primarily on postsynaptic neurons. These receptors are found throughout the nervous system as well as on blood platelets, where they mediate the actions of serotonin. The serotonin receptors are categorized into multiple subtypes based on differential affinity for various ligands $(5,6)$. Briefly, the evolving data suggest that serotonin receptors can be categorized into three major families: $5-\mathrm{HT}_{1}, 5-\mathrm{HT}_{2}$ and $5-\mathrm{HT}_{3}$. The $5-\mathrm{HT}_{1}$ class is reported to be heterogeneous and subdivided into the $5-\mathrm{HT}_{1 \mathrm{~A}},{ }_{1 \mathrm{~B}},{ }_{1 \mathrm{C}}$ and ${ }_{\mathrm{ID}}$ receptors. The original pharmacological distinctions have been confirmed by studies that have shown that each subtype is unique on the basis of anatomical distribution, signal transduction, physiological behavior and molecular composition.

\section{Serotonin Uptake Sites}

Early studies report controversial evidence for a reduction in the number of serotonin uptake sites both in platelets and brains of patients with major depression $(12,27,28,29,30)$. These results are complicated inpart by recent indications that several of the ligands used (e.g. impramine) recognize receptors of other neurotransmitters and therefore lack 5-HT binding specificity.

Experiments with more selective ligands (e.g. paroxetine) have indicated a significant reduction in the density of 5-HT uptake sites both in platelets and brain tissue of depressed patients when compared to age-matched controls (28). Consistent with the serotonin deficiency hypothesis, a loss of platelet 5-HT uptake would be expected to result in a loss of available serotonin to the nervous system. In the brain, a reduction in 5-HT uptake would be expected to increase the amount of available serotonin in the synaptic cleft. Indeed, the antidepressant fluoxetine is thought to exert its effects by blocking the same serotonin uptake mechanisms. It is curious that these same sites are reduced in the depressed patient. This also challenges the proposition that too little serotonin is a causal factor in depression. One reviewer suggests that the decrease in serotonin uptake sites may reflect a compensatory mechanism whereby a primary reduction in 5-HT induces a decrease in serotonin uptake at serotoninergic terminals in order to increase available 5-HT in the synaptic cleft (27). This interesting proposition would suggest that, when challenged by a reduction in 5-HT, the brain's own mechanism for maintaining available serotonin mimics the action of some drugs by decreasing the amount of 5-HT available to the postsynaptic neuron. It remains to be resolved whether the noted loss of 5-HT neuronal uptake signifies a primary deficit or a secondary compensatory response to serotonin loss. 


\section{Serotonin Receptors}

A review of the literature pertaining to the $5-\mathrm{HT}_{2}$ receptor found three of four studies which reported an increase in $5-\mathrm{HT}_{2}$ sites in the cortex of suicide victims $(31,32,33,34)$. Similarly, one study has reported an increase in prefrontal $5-\mathrm{HT}_{2}$ receptors in the brains of depressed patients (35). These findings support the serotonin deficiency model of depression whereby a reduction in serotonin results in a subsequent up-regulation of postsynaptic 5- $\mathrm{HT}_{2}$ receptors. Conversely, 5- $\mathrm{HT}_{2}$ receptors are down-regulated by a variety of antidepressants, including MAO inhibitors and 5-HT uptake inhibitors (e.g. impramine). Further, high affinity 5- $\mathrm{HT}_{2}$ antagonists (e.g. mianserin) which have significant clinical value, have also been shown to selectively decrease $5-\mathrm{HT}_{2}$ receptors $(36,37)$. This does not imply that drug treatment directly induces receptor down-regulation. Theoretically, antidepressants may induce $5-\mathrm{HT}_{2}$ receptor down-regulation as an indirect consequence of increasing available serotonin.

It is unclear, however, whether intact serotoninergic neurons are necessary for the down-regulation of associated receptors $(38,39)$. In fact, selective lesions of serotoninergic neurons does not consistently cause $5-\mathrm{HT}_{2}$ receptor up-regulation. Lesions of catecholamine-containing neurons (e.g. basal forebrain) do, however, result in receptor up-regulation of $5-\mathrm{HT}_{2}$ receptors (39). It is possible, therefore, that alterations in $5-\mathrm{HT}_{2}$ receptors depend on interactions with other transmitter pathways through unknown mechanisms. In fact, a recent publication reports a reduction in tryosine hydroxylase, the rate-limiting enzyme of catecholamine synthesis, in depression (40).

In contrast to its antidepressant action, it is interesting to note that electroconvulsive shock treatment causes an up-regulation of $5-\mathrm{HT}_{2}$ receptors (41). Further, this effect is selectively dependent on intact serotoninergic neurons (38). It must be noted, however, that electroconvulsive shock therapy has widespread effects which may have value independent of its action on the serotonin system.

Compared to the $5-\mathrm{HT}_{2}$ receptor class, studies of the $5-\mathrm{HT}_{1}$ receptors are more preliminary. In part, the difficulty in defining the role of $5-\mathrm{HT}_{1}$ receptors in depression reflects the lack of selective ligands for this receptor class. And, unlike the $5-\mathrm{HT}_{2}$ receptors which occupy a postsynaptic position, the $5-\mathrm{HT}_{1}$ receptors are found postsynaptically and presynaptically on serotoninergic neurons (autoreceptors) and nonserotoninergic neurons (heteroreceptors) $(5,6)$. Early studies which did not discriminate between $5-\mathrm{HT}_{1}$ receptors failed to find a reduction in total receptor content $(31,45,46)$. However, selective investigation of the $5-\mathrm{HT}_{1 \mathrm{~A}}$ receptor have shown a significant increase $(30 \%)$ in receptors in the brains of suicide victims when compared to controls $(47,48)$.

The receptor binding experiments demonstrate that depression is associated with a reduction of serotonin uptake sites and an up-regulation in some classes of 5 -HT receptors. The challenge is to integrate the independent findings into a unifying hypothesis. One interpretation would suggest that a primary loss in serotonin itself induces compensatory alterations in receptor content whereby postsynaptic 
sites up-regulate and presynaptic 5-HT uptake sites down-regulate. The net effect of such a dynamic would be to increase available serotonin (via uptake down-regulation) while amplifying postsynaptic effectiveness (via postsynaptic up-regulation). Again, these events would signify an adaptive receptor response to a deficiency in serotonin.

An alternative hypothesis postulates that alterations of 5-HT receptors represent a primary or initiating factor, as opposed to the compensatory response. This would imply that an increase in net serotonin transmission mediates depressive symptoms due to excessive serotonin at the synapse as well as an amplification of the signal at the postsynaptic site. As a consequence, levels of serotonin and its metabolite may be expected to drop.

The critical distinction between these hypotheses is whether the primary defect occurs pre or postsynaptically. The latter model would imply that increases in serotonin activity mediate depression through an alteration in serotonin receptors. Several lines of evidence presented previously contradict the serotonin deficiency hypothesis presented first and supported the latter concept that depression may be associated with excessive serotonin transmission and/or altered postsynaptic activity. For example, some antidepressants exert their effects by blocking and/or downregulating postsynaptic 5-HT receptors. In addition, the fact that serotonin denervation fails to alter the concentration of some receptors suggests that up-regulation occurs exclusive to reductions in available serotonin.

One study has attempted to distinguish between the roles of pre versus postsynaptic events in animal models of depression (51). Depression was induced by the administration of 5-HT or tetrabenazine and defined in terms of degree of animal activity. In the "depressive" state, specific uptake blockers of serotonin (e.g. fluoxetine) were found to potentiate the depressive symptoms substantially (200\%). The increases in depressive behavior were correlated with increases in brain 5-HIAA, the principle serotonin metabolite. In contrast, postsynaptic blockade of serotonin receptors (e.g. methylsergide) almost completely abolished the depressive action of 5-HT. Similarly, serotonin-induced depression was abolished by some antidepressants (e.g. mianserin, imipramine) which exert their effects by blocking serotonin postsynaptically. Taken together, the data imply that depression may be mediated postsynaptically and induced by excess transmission of serotonin at the synapse.

To further define the functional roles of $5-\mathrm{HT}_{1 \mathrm{~A}}$ receptors in depression, experiments have analyzed physiological responses associated with $5-\mathrm{HT}_{\mathrm{IA}}$ receptor activation. As mentioned, neuroendocrine parameters are frequently monitored as a functional indicator of serotonin activity. Compared to human controls, depressed patients show attenuated hypothalamic and neuroendocrine (e.g. ACTH, cortisol) responses to selective $5-\mathrm{HT}_{1 \mathrm{~A}}$ agonists $(49,50)$. This finding was somewhat specific for depression when compared to individuals with bipolar disorder or obsessivecompulsive illness. Thus, alterations of $5-\mathrm{HT}_{1 \mathrm{~A}}$ receptor and/or its signal transduction pathway appear to play a specific role in depression. The importance of this observation is that the depression-associated changes within the serotonin system may extend beyond alterations in 5-HT content and involve diminished functional effectiveness. 
In summary, there is substantial evidence to suggest that depression is associated with a reduction in serotonin uptake sites as well as an increase in some classes of serotonin receptors. It is not known whether the receptor alterations represent a primary defect or a secondary consequence of lowered serotonin content. The serotonin theory has yet to unequivocally assign a cause versus effect role to the many variables known to be altered in depression. Although the underlying dynamics are unresolved, the literature typically defines the serotonin system as being "deficient" in affective illness. This description can be interpreted as either a reduction in serotonin and/or a loss in receptor-mediated signal.

\section{CONCLUSIONS AND FUTURE DIRECTIONS}

The role of serotonin in affective illness is based in part on the following pathophysiological changes found in depression: 1) decreased brainstem 5-HT and/or 5-HIAA, 2) increased plasma tryptophan clearance, 3) that reduction in tryptophan induces depressive episodes in the depressed, 4) that serotonin uptake sites downregulate while some classes of serotonin receptors up-regulate, 5) that neuroendocrine activity is subresponsive to serotonin stimulation and 6) that many effective antidepressant therapies increase serotoninergic activity. To date, no unifying theory can account for the observed changes in the serotonin system as either a cause or consequence of depression.

The involvement of other transmitter systems in depression has not been addressed due to the limited scope of this review. It is probably inaccurate to assume that depressive illness involves a selective impairment within the serotoninergic system. In fact, the broader description of depression as an amine deficiency has been expanded based on current concepts which emphasize the dependent interrelationship between neurotransmitter systems $(52,53,54,57)$. This interaction is based on well-documented reports that multiple transmitters are co-localized within the same neuron. Moreover, the actions of distinct neurotransmitters are coupled at the level of transduction. For example, serotonin utilizes $G$ proteins, second messengers and ion channels which are also activated by other neurotransmitters and peptides. In other words, serotonin alters neuronal responsiveness through its shared interaction with other neurotransmitters/peptides. Thus, there is an ever increasing challenge to the description of "deficits" in terms of single transmitter systems. Further, depression may represent an alteration in signal transduction such that serotonin is susceptible to dysfunction through its association with these second messengers.

It is also important to note that changes within the serotonin axis do not account for the widespread pathological changes found in depressive illness. For example, depression is associated with the following abnormalities: lowered $\mathrm{Na}^{+}-\mathrm{K}^{+}$ATPase activity, lowered $\mathrm{Ca}^{++}-\mathrm{Mg}^{++}$ATPase activity, lowered adrenergic beta2 receptor activity and increased adrenergic-alpha2 receptor number/activity (55). Based on these observations, there is strong implication for the role of some abnormality with widespread pathogenic consequences in depressive illness. Similarily, there are few 
references in the literature to mechanisms which may induce or initiate serotonin dysfunction in depression.

The description of depression as a serotonin "deficiency" has followed the direction of basic research from a focus on transmitter deficiencies, to impaired signaling mechanisms. The emphasis on cellular function complicates the interpretation of data as it relates to depression. For example, the level of receptor content does not necessarily correlate with degree of function as a single receptor has been shown to amplify signals through the activation of multiple $\mathrm{G}$ protein molecules $(56,57)$. Therefore, a future challenge will be the translation of basic research to behavioral significance. Specifically, in order to understand the role of serotonin in depression, future studies are needed to determine the interrelationship between serotonin and other physiological mediators that are also known altered in depression.

\section{REFERENCES}

1. Meltzer HY: Role of serotonin in depression. Ann NY Acad of Sci 1990; 600:486-499

2. Meltzer HY, Lowy MT: The Serotonin Hypothesis of Depression, in Psychopharmacology: The Third Generation of Progress. Edited by Meltzer HY. New York, Raven Press, 1987

3. Nagayama $\mathrm{H}$, et al: Animal study on the role of serotonin in depression. Prog NeuroPsychopharmacol and Biol Psychiatry 1991; 15:735-744

4. Steinbusch HWM: Distribution of serotonin-immunoreactivity in the central nervous system of the rat-cell bodies and terminals. Neuroscience 1981;6:557-618

5. Frazer A, et al: Subtypes of serotonin receptors. Ann Rev of Pharm Toxicol 1990; 30:307-348

6. Peroutka SJ: 5-hydroxytryptamine receptor subtypes: molecular, biochemical and physiological characterization. TIPS 1988; 11:496-500

7. Stanely M, et al: Correlations between aminergic metabolites simultaneously obtained from human CSF brain. Life Sci 1985; 37:1279-1286

8. Roy A, et al: Cerebrospinal fluid monoamine and monoamine metabolite concentrations in melancholia. Psychiatry Res 1985; 15:281-292

9. Agren H: Symptom patterns in unipolar and bipolar depression correlating with monoamine metabolites in the cerebrospinal fluid: 1. general patterns. Psychiatry Res 1980; 3:211-223

10. Banki CM, et al: Cerebrospinal fluid amine metabolites, tryptophan and clinical parameters in depression. J of Affective Disord 1981; 3:81-89

11. Bowden CL, et al: Effects of amitriptiline and imipramine on brain amine neurotransmitter metabolites in cerebrospinal fluid. Clini Pharmacol Therap 1985; 37:316-324

12. Mann JJ, et al: Evidence of the serotonin hypothesis of suicide: A review of postmortem studies. Br J Psychiatry 1989; 155:7-14

13. Mann JJ, et al: Serotonin and suicidal behavior. Ann NY Acad of Sci 1990; 600:476-484

14. Cowen PJ, et al: Platelet 5-HT receptor binding during depressive illness and tricyclic antidepressant treatment. J Affective Dis 1989; 13:45-50

15. Smith DF, Stromgren LS: Influence of unilateral ECT on tryptophan metabolism in endogenous depression. Pharmacopsychiatry 1981; 14:135-138

16. Koyama T, Meltzer HY: A Biochemical and Endocrine Study of the Serotoninergic System in Depression, in New Results in Depression. Edited by Hippius H, et al. Berlin, SpringerVerlag, 1986 
17. Bovier P, et al: Evolution of red blood cell membrane transport and plasma level of L-tryptophan in depressed treated patients according to clinical improvement. Neuropsychobiology 1988; 19:125-134

18. Gaillard Jm, Tissot R: Blood-brain movements of tryptophan and tryosine in manicdepressive illness and schizophrenia. J Neural Trans 1979; 15:189-196

19. Shopsin B, et al: The Neuropsychopharmacology of Mania, in Drug Treatment of Mental Disorders. Edited by Simpson LL. New York, Raven Press, 1976

20. Delgado PL, et al: Serotonin function and the mechanism of antidepressant action. Reversal of anti-depressant induced remission by rapid depletion of plasma tryptophan. Arch Gen Psychiatry 1990; 47:411-418

21. Smith WK: The stress analogy. Schiz Bull 1987; 13:215-225

22. Glassmann AM, Platman SR: Potentiation of a monoamine oxidase inhibitor by tryptophan. Psychiatry Res 1969; 7:83-88

23. Louie AK, Meltzer HY: Lithium potentiation of antidepressant treatment. J of Clinical Psychopharmacology 1984; 4(6):316-322

24. Meltzer HY, et al: Effect of 5-hydroxytryptophan on serum cortisol levels in the major affective disorders and normal controls. I. Enhanced response in depression and mania. Arch Gen Psychiatry 1984; 41:366-374

25. Meltzer HY, et al: Effect of antidepressants, lithium and electroconvulsive treatment on rat serum prolactin levels. Acta Psychiat Scand 1980; 63:100-121

26. Glue PW, et al: The effect of lithium on 5-HT-mediated neuroendocrine responses and platelet 5-HT receptors. Psychopharmacology 1986; 90:398-402

27. Meltzer HY, et al: Serotonin uptake in blood platelets of psychiatric patients. Arch Gen Psychiatry 1987; 30:1322-1326

28. D'Haenen H, et al: Platelet H-paroxetine binding in depressed patients. Psychiatry Res 1988; $26: 11-17$

29. Stanely M, et al: Tritiated imipramine binding sites are decreased in the frontal cortex suicides. Science 1982; 216:1337-1339

30. Gross-Isserof R, et al: Autoradiographic analysis of tritiated imipramine binding in the human post mortem: Effects of suicide. Arch Gen Psychiatry 1989; 46:237-241

31. Crow TJ, et al: Neurotransmitter receptors and monoamine metabolites in the brains of Alzheimer-type dementia and depression and suicides. Neuropharmacology 1984; 23:15611569

32. Meltzer HY, et al: Neuroendocrine and biochemical studies of serotonin and dopamine in depression and suicide. International Confer on New Dir in Affective Disorders S60, 1987

33. Stanely M, Mann JJ: Increased serotonin-2 binding sites in frontal cortex of suicide victims. The Lancet 1983; i:214-216

34. Mann JJ, et al: Increased serotonin-2 and beta-adrenergic receptor binding in the frontal cortex of suicide victims. Arch Gen Psychiatry 1986; 43:954-959

35. Ferrier IN, et al: Postmortem neurochemical studies in depression. Ann NY Acad Sci 1986; 487:128-142

36. Blackshear MA, Sanders-Bush E: Serotonin receptor sensitivity after chronic and acute treatment with mianserin.J Pharmacol Exp Ther 1982; 2221:303-308

37. Deakin JF: 5- $\mathrm{HT}_{2}$ receptors, depression and anxiety. Pharmacol Biochem and Beh 1988; 29:819-820

38. Stockmeier CA, Keller KJ: In vivo regulation of serotonin-2 receptor in rat brain. Life Sci 1986; 38:117-127 
39. Roth BL, et al: Characterization of two $[\mathrm{H}]$ ketanserin recognition sites in rat striatum. J Neurochem 1987; 49:1833-1838

40. Biegon A: Reduced tyrosine hydroxylase immunoreactivity in locus coerulus of suicide victims. Neuro Sci Abstr 1991; 17:586.1

41. Keller KJ, et al: Differential effects of electroconvulsive shock and antidepressant drugs on serotonin-2 receptors in rat brain. Eur J Pharmacol 1981; 69:515-518

42. McBride PA, et al: Characterization of serotoninergic binding sites on human platelets. Life Sci 1987; 33:2033-2041

43. Biegon A, et al: Serotonin 5- $\mathrm{HT}_{2}$ receptor binding on blood platelets- A peripheral marker for depression. Life Sci 1987; 41:2485-2492

44. Cowen F, et al: Platelet 5-HT receptor binding during depressive illness and tricyclic antidepressant treatment. J Aff Dis 1987; 13:45-50

45. Owen F, et al: Brain 5- $\mathrm{HT}_{2}$ receptors and suicide. Lancet 1983; 2:1256

46. Owen FJ, et al: Serotoninergic mechanisms in the brains of suicide victims. Brain Res 1986; 362:185-188

47. Arango V, et al: Quantitative autoradiography of 5-HT $\mathrm{HA}_{\mathrm{AA}}$ binding in suicide. Neurosc Abst $1991 ; 17: 586.3$

48. Cheetem SC, et al: Brain 5-HT 1 binding sites in depressed suicides. Psychopharmacol $1990 ; 102: 544-548$

49. Lesch KP: 5-HT ${ }_{1 \mathrm{~A}}$ receptor responsivity in anxiety disorders and depression. Prog NeuroPharmacol and Biol Psychiatry 1991; 15:723-733

50. Curzon G: 5-Hydroxytryptamine and corticosterone in an animal model of depression. Prog Neuro-Pharmacol and Biol Psychiatry 1989; 13:305-310

51. Nagayama H, et al: Animal study on the role of serotonin in depression. Prog NeuroPharmacol and Biol Psychiatry 1991; 15:735-744

52. Nicoll RA: The coupling of neurotransmitter receptor to ion channels in the brain. Science 1988; 241:545-551

53. Steward O: Principles of cellular, molecular and developmental neuroscience. New York, Springer-Verlag, 1988

54. Sanders-Bush E: The serotonin receptors. New Jersey, Clifton Press, 1988

55. Hibbelin JR, et al: Are disturbances in lipid-protein interactions by phospholipase $\mathrm{A}_{2}$ a predisposing factor in affective illness. Biol Psychiatry 1989; 25:945-96 I

56. Ross EM: Signal sorting and amplification through G protein-coupled receptors. Neuron 1989; 3:141-152

57. Kandel ER, Schwartz JH: Principle of Neuroscience. New York, Elsevier Science, 1992 